UNDERGRADUATE RESEARCH IN NATURAL AND CLINICAL SCIENCE AND TECHNOLOGY (URNCST) JOURNAL Read more URNCST Journal articles and submit your own today at: https://www.urncst.com

\title{
COVID-19 and Its Implications on Social Engagement, Physical Activity, and Psychological Well-being for Older Adults with Alzheimer's Disease: A Systematic Review
}

\author{
Cherise Kwok, BSc Student [1]*, Megan Pan, BSc Student [1], Gwen Farm, BSc Student \\ [1] Faculty of Science, University of British Columbia, Vancouver, British Columbia, V6T $1 Z 4$ \\ *Corresponding Author: shareese@student.ubc.ca
}

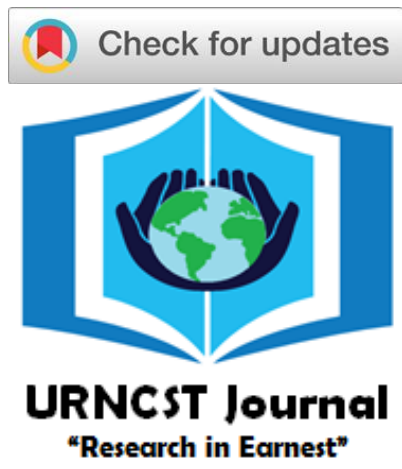

\begin{abstract}
Introduction: The coronavirus disease 2019 (COVID-19) pandemic has drastically disrupted daily routines, imposing rules such as social distancing and isolation that limit flexibility in one's social environment. These restrictions may spur the rate of cognitive decline in older adults, increasing the risk of Alzheimer's disease (AD) and exacerbating symptoms such as memory loss, impaired spatial awareness and language. These mandates may also hinder physical activity engagement, further increasing the risk of mental health problems and accelerating cognitive decline. As social interaction and physical activity form components of cognitive reserve, older adults may now face a higher risk of AD and faster AD progression. This paper will review the literature examining how the COVID-19 pandemic has affected the rate of cognitive decline in older adults in terms of AD pathology in three domains: social, physical, and psychological factors.

Methods: This systematic review summarizes the literature examining the relationship between social engagement, physical activity, and psychological well-being on cognitive decline in older adults. Electronic databases (PubMed, ScienceDirect, Web of Science, Google Scholar, and PsycINFO) were searched with the following keywords: "COVID-19, social isolation, Alzheimer's, cognitive decline, physical activity, social, psychological".

Results: Social engagement and physical activity can reduce the rate of cognitive decline and decrease the risk of AD and other dementias. Given that social, physical, and psychological factors have been impacted by pandemic restrictions, studies show this may result in greater cognitive decline in the years to follow. This is exacerbated due to the comorbidity between psychological distress and AD symptoms.

Discussion: The results of this study can be further explored to develop an intervention that can mitigate the negative effects of pandemic restrictions in individuals with AD. Overall, preventative strategies targeting factors of cognitive reserve should be urgently implemented for disadvantaged populations with a focus on older adults.

Conclusion: Clarifying the relationship between the COVID-19 restrictions and its effects on cognitive decline in AD will improve the health and well-being of older adults in the present and future. Understanding these effects on cognitive decline in $\mathrm{AD}$ has broader implications regarding individual responses to COVID-19 restrictions, and its associations with social engagement, physical activity, and psychiatric disorders in aging.
\end{abstract}

Keywords: COVID-19; Alzheimer's; cognitive decline; social isolation; physical activity; social; psychological

\section{Introduction}

The coronavirus disease 2019 (COVID-19) pandemic has robbed the lives of many, drastically altering the physical and mental well-being of millions on a global scale. With severe shortages of medical resources, uncertain prognoses, and strict and unfamiliar public health guidelines that limit personal freedoms and social behaviours, individuals with existing medical conditions that require continuous support and attention are faced with an even greater burden. Amidst the COVID-19 pandemic, the fear of dementia continues to persist in the aging population. With more than 50 million people affected by dementia [1], the health of our aging population is more vulnerable now than ever.

Kwok et al. | URNCST Journal (2021): Volume 5, Issue 7

DOI Link: https://doi.org/10.26685/urncst.260
Alzheimer's disease (AD) is a neurodegenerative disorder affecting more than 37 million people worldwide [2]. It is characterized by memory loss, disoriented behaviour, and impairments in language, comprehension, and spatial skills [2]. There is currently no cure for AD; current drugs are symptomatic but do not resolve the underlying pathological mechanisms of the disease [3]. As $\mathrm{AD}$ is the most common cause of dementia [4], it is important to understand how older adults with $\mathrm{AD}$ and those at risk of $\mathrm{AD}$ have been affected during the COVID-19 pandemic.

Cognitive reserve (CR) postulates that individual differences in the cognitive processes or neural networks underlying task performance allow some to cope better than others in spite of neurodegenerative damage [5]. Essentially, 
UNDERGRADUATE RESEARCH IN NATURAL AND CLINICAL SCIENCE AND TECHNOLOGY (URNCST) JOURNAL Read more URNCST Journal articles and submit your own today at: https://www.urncst.com

cognitive reserve can provide an explanation for the disparity seen amongst individuals who have normal cognition despite underlying $\mathrm{AD}$ pathology, as well as those with less severe AD pathology but severe cognitive deficits [6]. It is important to identify factors that affect cognitive reserve in older adults at risk of $\mathrm{AD}$ as it aids prevention and helps identify better interventions to help counteract clinical progression [7]. Amongst these interventions, many studies have also found evidence of proxies that can enhance cognitive reserve later in life by maintaining an active lifestyle and regular social engagement [8-9]. As such, AD and dementia risk are anticipated to be hampered by the pandemic socially, physically, and psychologically.

Although previous studies focused on the effects of exercise on sleep [10-11] or functional mobility [12-13] in older adults with dementia, limited research has examined this relationship on cognition. It is unclear whether longterm efforts in the prevention of $\mathrm{AD}$ and other dementias may be counteracted by lockdown measures. Since older individuals are more susceptible to neurodegenerative diseases, examining how preventative protective factors have been influenced by the pandemic is urgent. Previous studies have found that behavioural and psychological symptoms of dementia (BPSD), including depression and anxiety, occur in over $80 \%$ of individuals with AD [4]. The COVID-19 pandemic and social isolation in particular may exacerbate these psychiatric symptoms especially in the older adult population. With pandemic guidelines, it is unclear how individuals with AD and other dementias will respond to the long-term effects of isolation. As these changes impede the cognitive reserve of older individuals, it is hypothesized that a greater prevalence of $\mathrm{AD}$ will occur in the future. Recently emerging studies have started to analyze the effects of social isolation on cognitive decline [14]. Given the vulnerability of this group to physical and mental health problems, health professionals will require more information to help mitigate the adverse psychological consequences of social isolation.

This paper aimed to review existing literature on cognitive reserve of older adults with dementia, focusing on factors that affect AD during COVID-19 in particular. A three-pronged approach was taken in our review of the literature, specifically examining the impacts of social engagement, physical activity (PA), and psychological wellbeing in this population.

\section{Methods}

This systematic review will examine the literature pertaining to the relationship between pandemic restrictions and the respective outcomes on cognitive decline in relation to Alzheimer's disease. Electronic databases used include PubMed, ScienceDirect, Web of Science, Google Scholar, and PsycINFO and the following keywords were searched: "Alzheimer's", "social", "psychological”, "physical activity", "pandemic", "COVID-19". A total of 59 articles were analyzed. This consisted of 28 independent studies, 19 reviews, 2 meta-analyses, 1 editorial, 5 perspective articles, and 4 clinical trials. Of these articles, 15 were published during the COVID-19 era. Articles discussing Alzheimer's dementia were prioritized, though articles discussing other dementias such as vascular dementia, Lewy body dementia, and frontotemporal dementia were not excluded. Inclusion criteria included articles from peer-reviewed journals. The exclusion criteria included conference abstracts and protocols.

\section{Results}

This section will be divided into two sections: the first regarding literature that explores cognitive reserve factors of AD (i.e., social, physical, and psychological domains) and the second, reviewing preliminary studies how the COVID19 pandemic has affected these factors.

\section{Cognitive Reserve}

Social

A regular degree of social engagement has shown evidence of enhancing cognitive reserve and delaying the onset of AD pathology later life [8,15]. Meanwhile, a lack of social engagement can increase the rate of cognitive decline and risk of dementia [15]. Individuals who socially engage less and have smaller social networks display higher rates of cognitive decline [15]. Furthermore, older adults living alone without close social relations have a greater likelihood of developing dementia [16]. Notably, greater social isolation is associated with an increase in the presence of amyloid-beta $(\mathrm{A} \beta)$ whereas higher social engagement has a protective effect on cognitive function [15-16]. Interestingly, other studies which examined all-cause dementia found that greater social engagement (measured by the self-reported social network size, contentment with social relationships and feelings of being understood) was significantly correlated with greater cognitive ability (measured by performance on the mini-mental state examination and various tests assessing verbal fluency, episodic memory, abstract thinking, learning, and immediate visual memory) [17]. However, Marioni [17], did not find this relationship to be statistically significant amongst healthy older adults.

\section{Physical}

Existing literature also suggests that PA is protective of cognitive decline in older adults [19-24]. Importantly, PA has been shown to reduce risks of cognitive decline in various dementias, with greater effects for $\mathrm{AD}$ [22]. In a meta-analysis by Guure [22], researchers found that moderate and high PA are inversely proportional to dementia risk, reducing it by $21 \%$ and $24 \%$ for high and moderate PA respectively. For AD specifically, researchers found a reduced risk of 38\% (high PA) and 29\% (moderate PA). Furthermore, this study demonstrated sex differences in these protective effects such that men were found to have a lower dementia risk compared to women (i.e., a reduction of $39 \%$ compared to $36 \%$ respectively). Yaffe et al. [21] 
UNDERGRADUATE RESEARCH IN NATURAL AND CLINICAL SCIENCE AND TECHNOLOGY (URNCST) JOURNAL Read more URNCST Journal articles and submit your own today at: https://www.urncst.com

examined PA and longitudinal cognitive decline in older women where PA was measured by the number of city blocks walked and total caloric expenditure per week with any movement. Women with a higher baseline level of PA were found to be more protected from developing cognitive decline than those with lower baseline levels of PA. Mild PA was also found to reduce neuroinflammation of tau and $A \beta$ plaques, while moderate to high PA has been suggested to be neuroprotective through antioxidant enzymes and growth factors [20]. PA has also been found to enhance vascular changes in the brain, enhancing cerebral oxygenation and in turn, protecting against neuropathology in a sample of individuals with AD and other dementias [19]. However, while a majority of studies focus on the effects of aerobic exercise on cognitive health, other studies suggest more evidence is needed to determine specific PA guidelines for cognitive benefits [23-24]. For example, Eggermont et al. [25] found that cardiovascular risk factors may mask protective effects of PA on cognitive functioning in people with dementia.

\section{Psychological}

In terms of psychological disorders, anxiety and depression are often comorbid with AD. One study found that anxiety symptoms were quite common in individuals with AD, estimated to occur in $70 \%$ of the population [12]. There is also a high occurrence of anxiety in individuals with unspecified dementia [26]. Further, depression is the most common behavioural and psychological symptom in $\mathrm{AD}$, and individuals with depression are more impaired in cognition and activities of daily living compared to their healthy counterparts. Overall, depression often occurs more in individuals with $\mathrm{AD}$ (with prevalence estimates at around $30 \%$ ) than in healthy older adults over 65 years of age (with prevalence estimates of $0.4-1.4 \%$ ) [27]. The prevalence of psychological disorders in AD may have potential neurophysiological mechanisms. Research has found that positive $A \beta$ status was associated with a decline in cognitive domains such as memory and language, and these associations were moderated by elevated anxiety symptoms [29]. Furthermore, hyperactivation of the hypothalamicpituitary-adrenal axis, chronic inflammation, and the hippocampal-prefrontal cortex circuit was also strongly associated with depression in $\mathrm{AD}$, thus overlapping the neuropathology underlying these cognitive deficits $[2,29]$.

$\underline{\text { Research on the COVID-19 Pandemic }}$

Social

Due to the pandemic, many older individuals have reported having lost meaning and purpose in their lives [30]. In fact, the lack of social contact amongst older adults was found to be a key factor to feeling under-valued and nonpurposeful [30]. Ultimately, pandemic policies have had heavy repercussions on older adults, ranging from the cancellation of social activities, poor technological adaptation, as well as the lack of close contact for those living in residential homes [31]. Unfortunately, social distancing and isolation have also propagated loneliness which is associated with a greater rate of cognitive decline amongst older adults [32-34]. Nevertheless, multiple strategies have been established to counteract the effects of loneliness and social isolation. Amongst them include engaging in phone calls with friends which has been shown to improve emotional and social well-being amongst older adults [35]. Others have also attempted to cope by frequently employing self-enhancing comparisons (ie. pointing to those in worse circumstances) to preserve their sense of control over the current situation [30]. Overall, current literature suggests that older adults are the most vulnerable to the pandemic in terms of social isolation [37].

\section{Physical}

Given lockdown regulations, participation in PA programs has seen a general decline [37]. With this in mind, Yamada et al. [38] examined the effects of the COVID-19 pandemic on PA in older adults in Japan through a crosssectional online survey. Researchers found a significant decrease in total PA duration when comparing April 2020 (COVID-19 pandemic) to January 2020 (pre-COVID-19). Findings also suggest that this decline in PA could increase incidences of frailty and motor impairments in this population in the near future [38]. Older adults who met the World Health Organization's recommendation for PA levels reported higher resilience, positive affect, and lower depressive symptoms compared to their counterparts who did not regularly engage in PA [39-41]. Specifically, promoting PA can help cope with psychological distress especially surrounding social isolation [40]. Furthermore, researchers have found potential benefits of aerobic and resistance exercises that may increase vaccination responses by improving immune function and minimizing complications due to chronic diseases [40].

\section{Psychological}

The pandemic continues to differentially impact mental well-being of older adults across countries. In China, distress levels were measured from adolescents to older adults between 31 January 2020 to 10 February 2020 due to government implementation of more effective prevention and control measures [42]. Older adults above 60 years of age (as well as the 18 to 30 year-old age group) reported the highest levels of distress as measured by the COVID-19 Peritraumatic Distress Index (CPDI). In Italy, sociodemographic variables and self-reported levels of depression and anxiety were measured in a sample of adults that included older adults. Prediction models showed that those with infected acquaintances reported higher levels of depression and stress, and those with infected family members had higher anxiety levels [43]. In Germany, older adults who were more worried about COVID-19 had higher depressive symptoms and anxiety [44]. Interestingly, mental well-being and subjective ratings of loneliness levels were 
UNDERGRADUATE RESEARCH IN NATURAL AND CLINICAL SCIENCE AND TECHNOLOGY (URNCST) JOURNAL Read more URNCST Journal articles and submit your own today at: https://www.urnest.com

similar to rates before the pandemic occurred. In the United States, most older adults with pre-existing major depressive disorder had no difference in depression, anxiety, and suicidal ideation symptom scores compared to symptoms assessed before social distancing began [45]. This was taken as evidence for resilience in the first two months of the pandemic [45]. The authors highlighted the need for interventions to provide access to more social services. In Canada, there appears to be many barriers to interventions for loneliness and psychological distress, including access and familiarity with technology [36]. The authors highlight the critical need for technological literacy and better delivery methods, particularly for older adults who may lack technological experience.

In a study by Girdhar et al. [36], they reviewed mental health issues faced by older adults due to social isolation from the COVID-19 pandemic and explored methods to mitigate consequences. The authors emphasized that social isolation owing to the COVID-19 quarantines and lockdowns place a high risk on older adults' physical and psychological health as it may aggravate existing susceptibility of anxiety disorders, including phobias, obsessive-compulsive disorders, and post-traumatic stress disorder.

\section{Discussion}

In summary, social and physical engagement provide protective effects on cognitive functioning, reducing risks of cognitive decline in various dementias. This especially applies to older adults as they have a significantly higher susceptibility for AD. As depression and anxiety are often comorbid with $\mathrm{AD}$, these psychological disorders further impair cognition and exacerbate cognitive deficits. The lack of social contact amongst older adults from the COVID-19 pandemic has propagated loneliness, which may increase rates of cognitive decline. These restrictions have also reduced PA in older adults, with implications in higher incidences of motor impairments and chronic diseases while also perpetuating psychological distress, depression, and anxiety, and decreasing one's resilience. Given that the pandemic has modified social, physical, and psychological factors that affect $\mathrm{AD}$ and other dementias, we infer that a greater rate of age-related cognitive decline amongst the older population will come in the years to follow. Ultimately, social, physical, and psychological factors are all imperative for the maintenance of cognitive reserve [8,9]. In particular, certain tasks such as social engagement and increased PA may allow older adults to be more resilient against cognitive decline due to AD [46]. To our knowledge, no study has investigated how older adults with $\mathrm{AD}$ may be disproportionately affected during the pandemic compared to their healthy counterparts.

In terms of social consequences, research suggests evidence of consequential social isolation impacts that are specific to older adults with AD. As social connection is vital for communication, it has been proposed that those with low social engagement may receive less transmission of health information [47]. In addition, social engagement is positively associated with improved mental well-being and increased motivation for self-care [48]. Some studies have shown that less frequent positive social interaction may exacerbate the neuropathological progression of $\mathrm{AD}$. This has been supported by findings in the literature [15-16] demonstrating an increase in the presence of $A \beta$ amongst individuals with low social engagement. Ultimately, increased positive social engagement may allow older adults to be more resilient against cognitive decline [49]. Since research has shown that the long-term effects of social isolation can be moderated by cognitive reserve [50], social engagement interventions and programs should be prioritized to target older adults in the present and post-COVID-19 era. For example, implementations such as encouraging community centre participation following pandemic restrictions (allowing for social interaction and group PA) may decrease the rate of cognitive decline amongst older adults [51].

Although studies have suggested PA to be protective for AD and cognition [52-53], certain studies yielded mixed results [25]. For example, Eggermont et al. [25] underlined that cardiovascular risk factors such as hypoperfusion, abnormal nitric oxide levels, and hypertension may attenuate the beneficial effects of PA on cognition. This questions whether the presence of other factors that have not been studied would also moderate this relationship, particularly in $\mathrm{AD}$ and other dementias where the cardiovascular burden is high [25]. A review by Snowden et al. [54] found insufficient evidence of whether PA is protective for cognition. This is perhaps due to small sample sizes, low participant compliance [55], and difficulties understanding the program and treatment [56]. There is limited information disclosing the study's PA duration, intensity, and type [57]. The variance between studies can also be from the variability of assessments and measures different aspects of cognition [58]. Notably, PA (like other factors of cognitive reserve) may not directly improve cognition, rather improve one's psychological state by reducing depression which, in turn, may improve one's susceptibility to age-related cognitive decline [25,58-59]. Thus, while existing bodies of work are hopeful in advocating for the conferred benefits from PA on dementia and AD, more research needs to be conducted to reach a stronger consensus.

Overall, the pandemic has had a range of various global effects on the psychological well-being of multiple countries. Regional-specific measures must be implemented to help mitigate this variability of mental health consequences due to social isolation. More attention needs to be paid to psychiatric interventions that reduce psychological distress in older adults with $\mathrm{AD}$ in particular. Possible interventions include social facilitation or interaction services, psychological therapies, health and social care provisions, leisure skill development, and befriending interventions. In addition, the promotion of physical and social safety, hope, connectedness, resilience, and a sense of 
UNDERGRADUATE RESEARCH IN NATURAL AND CLINICAL SCIENCE AND TECHNOLOGY (URNCST) JOURNAL Read more URNCST Journal articles and submit your own today at: https://www.urncst.com

community may help control the adverse effects of social isolation. This would involve practical support for essential items, more frequent telephone contact with close connections, and online technologies to maintain social support networks. Overall, the implementation of preventative strategies for mental health consequences due to pandemic restrictions should be urgently implemented for disadvantaged older adult populations.

One major limitation is the reality that the pandemic is still ongoing at the time of writing this review and additional research on the effects of the pandemic has yet to be published. Furthermore, variability exists within pandemic safety procedures enforced by the public health authorities (e.g., duration of isolation) and general compliance. Thus, the present paper does not comprehensively summarize all experiences of the global population of those with AD and other dementias during the pandemic. In addition, caregivers were not taken into consideration within the review even though they may influence the cognitive reserve factors of AD, thus follow-up studies should be conducted in this area. Future longitudinal research should be conducted to identify long-term effects on cognitive reserve factors that increase AD progression in the post-COVID-19 era.

\section{Conclusions}

This study aimed to examine the social, physical, and psychological determinants affecting AD and dementia risk amongst older adults and how these determinants have been impacted in the context of the COVID-19 pandemic. While higher social engagement has protective effects on cognitive function, social restrictions imposed during the pandemic have caused older adults to feel a loss of meaning and purpose, increasing their vulnerability to AD. With lower amounts of PA during the pandemic, we expect lower resilience, lower positive affect, and higher depressive symptoms to persevere in the COVID-19 pandemic and beyond. Lastly, the compounding distress due to the COVID-19 pandemic is expected to increase older adult's susceptibility to such disorders. Given this, as anxiety and depression are often comorbid with $\mathrm{AD}$, mental distress from the COVID-19 may potentially exacerbate AD symptoms, worsening the prognoses of both psychiatric and neurodegenerative disorders. The increase in loneliness and psychological distress during the pandemic has exacerbated the mental health of older adults, thus potentially worsening existing symptoms of AD and other dementias. Ultimately, these findings can serve as a foundation in improving patient care in a post-COVID-19 era and aid in the promotion of healthy aging and AD prevention.

\section{List of Abbreviations Used}

AD: Alzheimer's disease

A $\beta$ : amyloid-beta

BPSD: behavioural and psychological symptoms of

dementia

COVID-19: coronavirus disease 2019

CPDI: COVID-19 peritraumatic distress index

CR: cognitive reserve

PA: physical activity

\section{Conflicts of Interest}

The author(s) declare that they have no conflicts of interest.

\section{Ethics Approval and/or Participant Consent}

This study did not require ethics approval and/or participant consent because this was a systematic review.

\section{Authors' Contributions}

CK: contributed to the study design and planning, drafted, and revised the manuscript, and gave final approval of the version to be published.

MP: contributed to the study design and planning, drafted, and revised the manuscript, and gave final approval of the version to be published.

GF: contributed to the study design and planning, drafted, and revised the manuscript, and gave final approval of the version to be published.

\section{Acknowledgements}

We would like to acknowledge our mentor, Ricky Chow, for his invaluable guidance, technical help, writing assistance, and contributions throughout this paper initiative.

\section{Funding}

This study was not funded.

\section{References}

[1] Alzheimer's Disease International. World Alzheimer report 2019 [Internet]. London: Alzheimer's Disease International; [cited 2021 Mar 31]. Available from: https://www.alzint.org/u/WorldAlzheimerReport2019. pdf

[2] Caraci F, Copani A, Nicoletti F, Drago F. Depression and Alzheimer's disease: Neurobiological links and common pharmacological targets. European Journal of Pharmacology. 2010 Jan;626(1):64-71. https://doi.org/ 10.1016/j.ejphar.2009.10.022

[3] Klafki H-W, Staufenbiel M, Kornhuber J, Wiltfang J. Therapeutic approaches to Alzheimer's disease. Brain. 2006 Sep 29;129(11):2840-55. https://doi.org/10.1093/ brain/awl 280

[4] Tsuno N, Homma A. What is the association between depression and Alzheimer's disease? Expert Review of Neurotherapeutics. 2009 Nov;9(11):1667-76. https://doi.org/10.1586/ern.09.106 
UNDERGRADUATE RESEARCH IN NATURAL AND CLINICAL SCIENCE AND TECHNOLOGY (URNCST) JOURNAL Read more URNCST Journal articles and submit your own today at: https://www.urncst.com

[5] Stern Y. Cognitive reserve. Neuropsychologia. 2009 Aug;47(10):2015-28. https://doi.org/10.1016/j .neuropsychologia.2009.03.004

[6] Riley KP, Snowdon DA, Markesbery WR. Alzheimer's neurofibrillary pathology and the spectrum of cognitive function: Findings from the nun study. Annals of Neurology. 2002 May;51(5):567-77. https://doi.org/ 10.1002/ana.10161

[7] van Loenhoud AC, van der Flier WM, Wink AM, Dicks E, Groot C, Twisk J, et al. Cognitive reserve and clinical progression in Alzheimer disease: A paradoxical relationship. Neurology. $2019 \mathrm{Jul}$ 23;93(4):e334-46. https://doi.org/10.1212/WNL .0000000000007821

[8] Evans IEM, Wu Y-T, Brayne C, Matthews F, Woods $\mathrm{B}$, Clare L. [P2-580]: Social isolation, cognitive reserve, and cognition in later life. Alzheimers \& Dementia. 2017 Jul;13(7S_Part_17):P869-P869. https://doi.org/10.1371/journal.pone.0201008

[9] Wikee G, Martella D. Capacidad física y reserva cognitiva como factores protectores de las funciones atencionales en adultos mayores. Revista Médica de Chile. 2018 May;146(5):570-7. http://dx.doi.org/ 10.4067/s0034-98872018000500570

[10] Alessi CA, Schnelle JF, MacRae PG, Ouslander JG, Al-Samarrai N, Simmons SF, et al. Does physical activity improve sleep in impaired nursing home residents? Journal of American Geriatrics Society. 1995 Oct;43(10):1098-102. https://doi.org/10.1111/ j.1532-5415.1995.tb07007.x

[11] Namazi KH, Zadorozny CA, Gwinnup PB. The Influences of physical activity on patterns of sleep behavior of patients with Alzheimer's disease. The International Journal of Aging and Human Development. 1995 Mar;40(2):145-53. https://doi.org/ 10.2190/Q1PQ-8MKY-XWHN-JH8M

[12] Teri L, Ferretti LE, Gibbons LE, Logsdon RG, McCurry SM, Kukull WA, et al. Anxiety in Alzheimer's disease: Prevalence and comorbidity. The Journals of Gerontology Series A: Biological Sciences and Medical Sciences. 1999 Jul 1;54(7):M348-52. https://doi.org/10.1093/gerona/54.7.M348

[13] MacRae PG, Asplund LA, Schnelle JF, Ouslander JG, Abrahamse A, Morris C. A walking program for nursing home residents: Effects on walk endurance, physical activity, mobility, and quality of life. Journal of the American Geriatrics Society. 1996 Feb;44(2):175-80. https://doi.org/10.1111/j.15325415.1996.tb02435.x

[14] Plassman BL, Jr JWW, Burke JR, Holsinger T, Benjamin S. Systematic review: Factors associated with risk for and possible prevention of cognitive decline in later life. Annals of Internal Medicine. 2010 Aug 3; 153(3):182-93. https://doi.org/10.7326/00034819-153-3-201008030-00258

Kwok et al. | URNCST Journal (2021): Volume 5, Issue 7 DOI Link: https://doi.org/10.26685/urnest.260
[15] Biddle KD, d'Oleire Uquillas F, Jacobs H, Zide B, Kirn DR, Rentz DM, et al. Social engagement and amyloid- $\beta$-related cognitive decline in cognitively normal older adults. The American Journal of Geriatric Psychiatry. 2019 Nov;27(11):1247-56. https://doi.org/ 10.1016/j.jagp.2019.05.005

[16] Zunzunegui M-V, Alvarado BE, Del Ser T, Otero A. Social networks, social integration, and social engagement determine cognitive decline in community-dwelling Spanish older adults. The Journals of Gerontology Series B: Psychological Sciences and Social Sciences. 2003 Mar 1;58(2):S93100. https://doi.org/10.1093/geronb/58.2.S93

[17] Marioni RE, Proust-Lima C, Amieva H, Brayne C, Matthews FE, Dartigues J-F, et al. Social activity, cognitive decline and dementia risk: A 20-year prospective cohort study. BMC Public Health. 2015 Dec;15(1):1089. https://doi.org/10.1186/s12889-0152426-6

[18] Fratiglioni L, Paillard-Borg S, Winblad B. An active and socially integrated lifestyle in late life might protect against dementia. The Lancet Neurology. 2004 Jun;3(6):343-53. https://doi.org/10.1016/S1474-4422 (04)00767-7

[19] Rashid MH, Zahid MF, Zain S, Kabir A, Hassan SU. The neuroprotective effects of exercise on cognitive decline: A preventive approach to Alzheimer's disease. Cureus. 2020 Feb 11. https://doi.org/10.7759/cureus .6958

[20] Yaffe K, Barnes D, Nevitt M, Lui L-Y, Covinsky K. A prospective study of physical activity and cognitive decline in elderly women: Women who walk. Archives of Internal Medicine. 2001 Jul 23;161(14):1703. https://doi.org/10.1001/archinte.161.14.1703

[21] Guure CB, Ibrahim NA, Adam MB, Said SM. Impact of physical activity on cognitive decline, dementia, and its subtypes: Meta-analysis of prospective studies. BioMed Research International. 2017;2017:1-13. https://doi.org/10.1155/2017/9016924

[22] van Gelder BM, Tijhuis MAR, Kalmijn S, Giampaoli S, Nissinen A, Kromhout D. Physical activity in relation to cognitive decline in elderly men: The fine study. Neurology. 2004 Dec 28;63(12):2316-21. https://doi.org/10.1212/01.WNL.0000147474.29994.35

[23] Phillips C, Akif Baktir M, Das D, Lin B, Salehi A. The link between physical activity and cognitive dysfunction in Alzheimer's disease. Physical Therapy. $2015 \mathrm{Jul}$ 1;95(7):1046-60. https://doi.org/10.2522/ ptj.20140212

[24] Jedrziewski MK, Lee VM-Y, Trojanowski JQ. Physical activity and cognitive health. Alzheimers \& Dementia. 2007 Apr;3(2):98-108. https://doi.org/10.1016/j.jalz $\underline{.2007 .01 .009}$ 
UNDERGRADUATE RESEARCH IN NATURAL AND CLINICAL SCIENCE AND TECHNOLOGY (URNCST) JOURNAL Read more URNCST Journal articles and submit your own today at: https://www.urncst.com

[25] Eggermont L, Swaab D, Luiten P, Scherder E. Exercise, cognition and Alzheimer's disease: More is not necessarily better. Neuroscience \& Biobehavioural Reviews. 2006 Jan;30(4):562-75. https://doi.org/ 10.1016/j.neubiorev.2005.10.004

[26] Ferretti L, McCurry SM, Logsdon R, Gibbons L, Teri L. Anxiety and Alzheimer's disease. Journal of Geriatric Psychiatry and Neurology. 2001 Mar;14(1):52-8. https://doi.org/10.1177/089198870 101400111

[27] Even C, Weintraub D. Case for and against specificity of depression in Alzheimer's disease: Depression in Alzheimer's disease. Psychiatry and Clinical Neurosciences. 2010 Aug;64(4):358-66. https://doi.org/10.1111/j.1440-1819.2010.02108.x

[28] Pietrzak RH, Lim YY, Neumeister A, Ames D, Ellis $\mathrm{KA}$, Harrington $\mathrm{K}$, et al. Amyloid- $\beta$, anxiety, and cognitive decline in preclinical Alzheimer disease: A multicenter, prospective cohort study. JAMA Psychiatry. 2015 Mar 1;72(3):284. https://doi.org/ 10.1001/jamapsychiatry.2014.2476

[29] Sampath D, Sathyanesan M, Newton S. Cognitive dysfunction in major depression and Alzheimer's disease is associated with hippocampus: Prefrontal cortex dysconnectivity. Neuropsychiatric Disease and Treatment. 2017 Jun;13:1509-19. https://doi.org/10.2147/NDT.S136122

[30] Verhage M, Thielman L, de Kock L, Lindenberg J. Coping of older adults in times of COVID-19: Considerations of temporality among Dutch older adults. The Journals of Gerontology: Series B. 2021 Jan 10. https://doi.org/10.1093/geronb/gbab008

[31] Gorenko JA, Moran C, Flynn M, Dobson K, Konnert C. Social isolation and psychological distress among older adults related to COVID-19: A narrative review of remotely-delivered interventions and recommendations. Journal of Applied Gerontology. 2021 Jan;40(1):3-13. https://doi.org/10.1177/0733464820958550

[32] Kuiper JS, Zuidersma M, Zuidema SU, Burgerhof JGM, Stolk RP, Oude Voshaar RC, et al. Social relationships and cognitive decline: A systematic review and meta-analysis of longitudinal cohort studies. International Journal of Epidemiology. 2016 Jun 6. https://doi.org/10.1093/ije/dyw089

[33] Balouch S, Rifaat E, Chen HL, Tabet N. Social networks and loneliness in people with Alzheimer's dementia. International Journal of Geriatric Psychiatry. 2019;34(5):666-73. https://doi.org/10.1002/gps.5065

[34] Weng X, George DR, Jiang B, Wang L. Association between subjective cognitive decline and social and emotional support in us adults. American Journal of Alzheimer's Disease \& Other Dementias. 2020 Jan 1;35:153331752092239. https://doi.org/10.1177/ 1533317520922392

Kwok et al. | URNCST Journal (2021): Volume 5, Issue 7

DOI Link: https://doi.org/10.26685/urncst.260
[35] Fingerman KL, Ng YT, Zhang S, Britt K, Colera G, Birditt KS, et al. Living alone during COVID-19: Social contact and emotional well-being among older adults. The Journals of Gerontology: Series B. 2021 Feb 17;76(3):e116-21. https://doi.org/10.1093/geronb/ gbaa200

[36] Girdhar R, Srivastava V, Sethi S. Managing mental health issues among elderly during COVID-19 pandemic. Journal of Geriatric Care and Research. 2020 Apr;7(1):32-35.

[37] Goethals L, Barth N, Guyot J, Hupin D, Celarier T, Bongue B. Impact of home quarantine on physical activity among older adults living at home during the COVID-19 pandemic: Qualitative interview study. JMIR Aging. 2020 May 7;3(1):e19007. https://doi.org/ $10.2196 / 19007$

[38] Yamada M, Kimura Y, Ishiyama D, Otobe Y, Suzuki M, Koyama S, et al. Effect of the COVID-19 epidemic on physical activity in community-dwelling older adults in Japan: A cross-sectional online survey. The Journal of Nutrition, Health \& Aging. 2020 Sep;24(9):948-50. https://doi.org/10.1007/s12603-0201501-6

[39] Carriedo A, Cecchini JA, Fernandez-Rio J, MéndezGiménez A. COVID-19, psychological well-being and physical activity levels in older adults during the nationwide lockdown in Spain. The American Journal of Geriatric Psychiatry. 2020 Nov;28(11):1146-55. https://doi.org/10.1016/j.jagp.2020.08.007

[40] Damiot A, Pinto AJ, Turner JE, Gualano B. Immunological implications of physical inactivity among older adults during the COVID-19 pandemic. Gerontology. 2020;66(5):431-8. https://doi.org/10 $.1159 / 000509216$

[41] Callow DD, Arnold-Nedimala NA, Jordan LS, Pena GS, Won J, Woodard JL, et al. The mental health benefits of physical activity in older adults survive the COVID-19 pandemic. The American Journal of Geriatric Psychiatry. 2020 Oct;28(10):1046-1057. https://doi.org/10.1016/j.jagp.2020.06.024

[42] Qiu J, Shen B, Zhao M, Wang Z, Xie B, Xu Y. A nationwide survey of psychological distress among Chinese people in the COVID-19 epidemic: Implications and policy recommendations. General Psychiatry. 2020 Mar;33(2):e100213. http://dx.doi.org/ 10.1136/gpsych-2020-100213

[43] Mazza C, Ricci E, Biondi S, Colasanti M, Ferracuti S, Napoli C, et al. A nationwide survey of psychological distress among Italian people during the COVID-19 pandemic: Immediate psychological responses and associated factors. International Journal of Environmental Research and Public Health. 2020 May 2;17(9):3165. https://doi.org/10.3390/ijerph17093165 
UNDERGRADUATE RESEARCH IN NATURAL AND CLINICAL SCIENCE AND TECHNOLOGY (URNCST) JOURNAL Read more URNCST Journal articles and submit your own today at: https://www.urncst.com

[44] Röhr S, Reininghaus U, Riedel-Heller SG. Mental wellbeing in the German old age population largely unaltered during COVID-19 lockdown: Results of a representative survey. BMC Geriatrics. 2020 Dec;20(1):489. https://doi.org/10.1186/s12877-020$\underline{01889-X}$

[45] Hamm ME, Brown PJ, Karp JF, Lenard E, Cameron F, Dawdani A, et al. Experiences of American older adults with pre-existing depression during the beginnings of the COVID-19 pandemic: A multicity, mixed-methods study. The American Journal of Geriatric Psychiatry. 2020 Sep;28(9):924-932. https://doi.org/10.1016/j.jagp.2020.06.013

[46] Stern Y. Cognitive reserve in ageing and Alzheimer's disease. The Lancet Neurology. 2012

Nov;11(11):1006-1012. https://doi.org/10.1016/S14744422(12)70191-6

[47] Kim W, Kreps GL, Shin C-N. The role of social support and social networks in health informationseeking behavior among Korean Americans: A qualitative study. International Journal for Equity in Health. 2015 Dec;14(1):40. https://doi.org/10.1186/ s12939-015-0169-8

[48] Thoits PA. Mechanisms linking social ties and support to physical and mental health. Journal of Health and Social Behaviour. 2011 Jun;52(2):145-161. https://doi.org/10.1177/0022146510395592

[49] Stern Y. Cognitive reserve: Implications for assessment and intervention. Folia Phoniatrica et Logopaedica. 2013;65(2):49-54. https://doi.org/ $\underline{10.1159 / 000353443}$

[50]Evans IEM, Llewellyn DJ, Matthews FE, Woods RT, Brayne C, Clare L, et al. Social isolation, cognitive reserve, and cognition in healthy older people. Ginsberg SD, editor. PLOS ONE. 2018 Aug 17;13(8):e0201008. https://doi.org/10.1371/journal .pone.0201008

[51] Hikichi H, Kondo K, Takeda T, Kawachi I. Social interaction and cognitive decline: Results of a 7-year community intervention. Alzheimers \& Dementia: Translational Research \& Clinical Interventions. 2017 Jan;3(1):23-32. https://doi.org/10.1016/j.trci.2016.11 .003
[52] Denkinger MD, Nikolaus T, Denkinger C, Lukas A. Physical activity for the prevention of cognitive decline: Current evidence from observational and controlled studies. Zeitschrift Für Gerontologie und Geriatrie. 2012 Jan;45(1):11-16. https://doi.org/ $\underline{10.1007 / \mathrm{s} 00391-011-0262-6}$

[53] Cass SP. Alzheimer's disease and exercise: A literature review. Current Sports Medicine Reports. 2017 Jan;16(1):19-22. https://doi.org/10.1249/JSR.0000000 $\underline{000000332}$

[54] Snowden M, Steinman L, Mochan K, Grodstein F, Prohaska TR, Thurman DJ, et al. Effect of exercise on cognitive performance in community-dwelling older adults: Review of intervention trials and recommendations for public health practice and research: Exercise for cognition in older adults. Journal of the American Geriatrics Society. 2011 Apr;59(4):704-716. https://doi.org/10.1111/j.15325415.2011.03323.x

[55] Tappen RM, Roach KE, Applegate EB, Stowell P. Effect of a combined walking and conversation intervention on functional mobility of nursing home residents with Alzheimer disease. Alzheimer Disease and Associated Disorders. 2000 Oct;14(4):196-201. https://doi.org/10.1097/00002093-200010000-00002

[56] Naso F, Carner E, Blankfort-Doyle W, Coughey K. Endurance training in the elderly nursing home patient. Archives of Physical Medicine and Rehabilitation. 1990 Mar;71(3):241-243.

[57] Hogervorst E. Exercise to prevent cognitive decline and Alzheimer's disease: For whom, when, what, and (most importantly) how much? Journal of Alzheimers Disease \& Parkinsonism. 2012; 2(3). https://doi.org/ $10.4172 / 2161-0460.1000 \mathrm{e} 117$

[58] Bierman EJM, Comijs HC, Jonker C, Beekman ATF. Effects of anxiety versus depression on cognition in later life. The American Journal of Geriatric Psychiatry. 2005 Aug;13(8):686-693. https://doi.org/ 10.1176/appi.ajgp.13.8.686

[59] Palmer C. Exercise as a treatment for depression in elders. Journal of the American Academy of Nurse Practitioners. 2005 Feb;17(2):60-66. https://doi.org/ $\underline{10.1111 / \mathrm{j} .1041-2972.2005 .00012 . \mathrm{x}}$ 
UNDERGRADUATE RESEARCH IN NATURAL AND CLINICAL SCIENCE AND TECHNOLOGY (URNCST) JOURNAL

Read more URNCST Journal articles and submit your own today at: https://www.urncst.com

\section{Article Information}

Managing Editor: Jeremy Y. Ng

Peer Reviewers: Ricky Chow, Jeremy Steen

Article Dates: Received Apr 03 21; Accepted Jun 01 21; Published Jul 1421

\section{Citation}

Please cite this article as follows:

Kwok C, Pan M, Farm G. COVID-19 and its implications on social engagement, physical activity, and psychological wellbeing for older adults with Alzheimer's disease: A systematic review. URNCST Journal. 2021 Jul 14: 5(7).

https://urncst.com/index.php/urncst/article/view/260

DOI Link: https://doi.org/10.26685/urncst.260

\section{Copyright}

(C) Cherise Kwok, Megan Pan, Gwen Farm. (2021). Published first in the Undergraduate Research in Natural and Clinical Science and Technology (URNCST) Journal. This is an open access article distributed under the terms of the Creative Commons Attribution License (https://creativecommons.org/licenses/by/4.0/), which permits unrestricted use, distribution, and reproduction in any medium, provided the original work, first published in the Undergraduate Research in Natural and Clinical Science and Technology (URNCST) Journal, is properly cited. The complete bibliographic information, a link to the original publication on http://www.urncst.com, as well as this copyright and license information must be included.

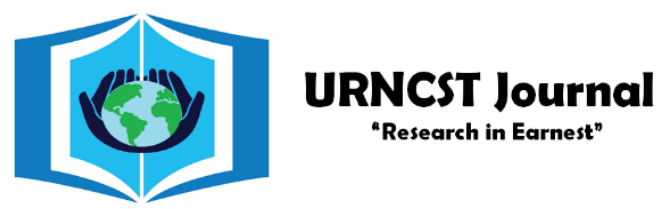

\section{Funded by the Government of Canada}

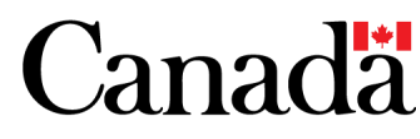

Do you research in earnest? Submit your next undergraduate research article to the URNCST Journal!

| Open Access | Peer-Reviewed | Rapid Turnaround Time | International | | Broad and Multidisciplinary | Indexed | Innovative | Social Media Promoted |

Pre-submission inquiries? Send us an email at info@ urncst.com | Facebook, Twitter and LinkedIn: @URNCST

Submit YOUR manuscript today at https://www.urncst.com! 